\title{
O papel do ego nas disfunções sexuais*
}

Laura Meyer da Silva**

\section{RESUMO}

O presente trabalho trata de uma tentativa de entendimento do funcionamento do ego e seu papel nas disfunções sexuais, utilizando para isto a compreensão de Freud sobre o Ego e a visão da Psicologia do Ego.

A Psicologia do Ego origina-se da segunda teoria da ansiedade de Freud (1923) e da Teoria Estrutural: Id, Ego e Superego. A partir destes conceitos fundamentais de Freud, que sempre se preocupou em compreender o funcionamento do ego, Hartmann organizou a Psicologia do Ego e mais tarde outros autores, seguidores desta escola, desenvolveram mais suas idéias.

A autora procura explicar o que são disfunções sexuais, desenvolve conceitos sobre sexualidade masculina e feminina dentro da visão freudiana e hartmaniana, ilustra com duas vinhetas o material e depois apresenta suas conclusões.

* Trabalho realizado na Santa Casa de Misericórdia de Porto Alegre-RS.

** Mestre em Psicologia Clínica pela PUC/RS. 


\section{INTRODUÇÃO}

Entende-se Disfunções Sexuais como manifestações no comportamento sexual de profundo distúrbio emocional, provocado por conflitos intrapsíquicos com os quais o ego não consegue lidar. Estes conflitos acabam se manifestando na vida sexual de homens e mulheres que encontram dificuldade em manter relações sexuais prazerosas com seus parceiros.

As disfunções sexuais encontradas com mais freqüência, das quais os pacientes se queixam e procuram auxílio para sua solução são:

- na mulher: frigidez (disfunção sexual geral), disfunção orgásmica e vaginismo;

- no homem: disfunção erétil (impotência) e ejaculação precoce ou retardada.

Conforme a teoria freudiana, as dificuldades que surgem na área sexual no menino têm origem na ansiedade de castração, e na menina a perda de amor. Para ambos, esta ansiedade é proveniente de um superego muito rígido que, segundo Freud (1923), é o herdeiro do complexo de Édipo. Ele provoca muita culpa e não permite a gratificação que o prazer genital proporciona.

A Psicologia do Ego defende a idéia de uma psicologia geral: "Teoria geral do desenvolvimento mental". Para ela, é importante levar em consideração todas as áreas da vida do homem e não dar ênfase somente aos conflitos, como propõe Freud.

Além da ansiedade de castração no menino e do medo da perda de amor para a menina, a importância da relação com os pais e a resolução do conflito edipiano, a psicologia do ego propõe, segundo Schafer (in Blum, 1982), ver a pessoa como um todo, num mundo complexo. Todos os aspectos do desenvolvimento seriam influenciados pela aprendizagem, num contexto de relações objetais que são: "de um lado, biologicamente essenciais e biologicamente dirigidas $e$, de outro, moldadas culturalmente e historicamente condicionadas" (p. 233).

Portanto, esse trabalho não pretende excluir nenhuma teoria, mas sim integrá-las, pois a Psicologia do Ego utiliza a teoria freudiana procurando ver o homem mais integrado com o mundo.

\section{O FUNCIONAMENTO DO EGO E A SEXUALIDADE EM FREUD}

Com o Ego e o Id (1923), Freud inaugura a segunda tópica, onde destaca uma parte inconsciente do ego. Explica que existe uma organização coerente de processos mentais dentro de cada um de nós e é a isto que cha- 
ma de ego. A consciência, também chamada por Freud de superfície do aparelho mental, acha-se ligada ao ego e ele é o responsável pela descarga de excitações para o mundo exterior. É também tarefa do ego colocar em ação a vontade do id, como se fosse uma vontade dele mesmo. O ego deriva de sensações corporais, ele próprio é a projeção mental de uma superfície do corpo, além de representar as superfícies do aparelho mental.

Um ponto muito importante que mudou na teoria freudiana foi a teoria da ansiedade, onde Freud (1923) passa a ver o ego como a sede real da ansiedade.

Em A Dissolução do Complexo de Édipo (1924), Freud descreve que a autoridade dos pais é introjetada no ego formando o núcleo do superego. O superego proíbe o incesto e defende o ego do retorno da catexia libidinal. "As tendências libidinais pertencentes ao Complexo de Édipo são em parte dessexualizadas e sublimadas (coisa que provavelmente acontece com toda transformação em uma identificação) e em parte são inibidas em seu objetivo e transformadas em impulsos de afeição" (p. 221). Se o ego não consegue muito mais que uma repressão do complexo, este continuará inconsciente no id, manifestando-se mais tarde de forma patogênica. A neurose se baseia, portanto, numa luta do ego contra as exigências da função sexual.

Em Algumas conseqüências psíquicas da distinção anatômica entre os sexos (1925), Freud ressalta a relação existe entre os sexos feminino e masculino e os complexos de Édipo e de castração, fazendo uma ressalva fundamental: "Enquanto, nos meninos, o complexo de Édipo é destruído pelo complexo de castração, nas meninas ele se faz possível e é introduzido através do complexo de castração" (p. 318). O complexo de Édipo nos meninos não é simplesmente reprimido, pois a ameaça de castração é uma constante. "Suas catexias libidinais são abandonadas, dessexualizadas, $e$, em parte, sublimadas: seus objetos são incorporados ao ego, onde formam o núcleo do superego e fornecem a essa nova estrutura suas qualidades características" (p. 319).

Em seu clássico estudo Três Ensaios sobre a Teoria da Sexualidade (1905), Freud explica que: "os sintomas representam um substituto para os impulsos de uma fonte cuja força se origina do instinto sexual". (...) "A psicanálise é em geral capaz de mostrar que a doença se tornou possível pelo componente sexual do conflito, que impediu os processos psíquicos de alcançar um resultado normal" (p. 167-8). É durante o período de latência (5-6 anos) término do complexo de Édipo, que vai do declínio da sexualidade infantil até o início da puberdade, que são construídas as forças psíquicas que mais tarde impedirão o curso do instinto sexual, restringindo seu fluxo: repugnância, vergonha e exigências dos ideais estéticos e morais. Essas barreiras são produto da educação, mas acrescidas pela hereditariedade $\mathrm{e}$ às vezes só por ela.

De acordo com Freud (1905), as disposições de ambos os sexos já são reconhecidas na infância. As inibições da sexualidade (vergonha, repugnân- 
cia, piedade, etc.) acontece nas meninas mais cedo do que nos meninos em função de menor resistência. Freud afirma que as meninas tem uma tendência maior à repressão sexual e são mais passivas que os meninos. Crianças com um instinto sexual excessivo, que desenvolveu-se prematuramente ou que foi muito mimada, tem a tendência a serem tímidas. Uma criança que transforma sua libido em ansiedade quando não pode satisfaze-la comportase como um adulto neurótico, ao passo que um adulto neurótico em virtude da insatisfação de sua libido comporta-se como uma criança.

Freud (1905) observa que moças que não suplantam a autoridade dos pais são na maioria aquelas que persistem em seu amor infantil muito além da puberdade. Mais tarde em seus casamentos são incapazes de relacionarse adequadamente com seus maridos, são frias e sexualmente anestesiadas. "O amor sexual e o que parece ser amor não sexual pelos pais se alimentam da mesma fonte; o último corresponde simplesmente a uma fixação infantil da libido" (Freud, 1905, p. 234).

Nos neuróticos, a atividade psicossexual na escolha de um objeto permanece no inconsciente em função de seu repúdio à sexualidade. Moças com repúdio à vida sexual, por um lado, desejam um amor assexual e por outro desejam ocultar sua libido através de relacionamentos que não sejam sentidos como censuráveis, afetos revividos da infância e puberdade. Freud (1905) chama atenção para o fato de que qualquer distúrbio na relação com os pais na infância produz efeito mais tarde na vida sexual adulta.

"A necessidade e a orientação sexuais constituem meramente um único fator em ação no mecanismo de neurose; se não houvesse outros, o resultado seria a dissipação, não a doença" (Freud, 1905 [1904], p. 278). Também a aversão que o neurótico sente pela sexualidade e a incapacidade de amar são, segundo Freud, esquecidos com facilidade. Somente quando surge um conflito entre essas duas tendências é que surge a doença nervosa; portanto, Freud considera que aconselhar o paciente a manter relações sexuais nas psiconeuroses só muito raramente seria considerado um conselho sensato.

Em Inibições, Sintoma e Ansiedade (1926 [1925]), Freud escreve que existem doenças em que se observa a presença de inibições, mas não de sintomas. Inibição tem uma relação com função, restrição, redução normal de uma função, não sendo necessariamente patológica. Uma inibição pode também ser um sintoma, porém se é sintoma então é patológico e os sintomas em conseqüência enfraquecem o ego.

Segundo Freud (1926 [1925]), "a função sexual está sujeita a grande número de perturbações, a maioria das quais exibe as características de inibições simples. Estas são classificadas em conjunto como impotência psíquica" (p. 108). A função sexual normal é o resultado de um processo muito complicado, sendo suscetível a distúrbio. Quanto ao sexo masculino, as inibições podem ocorrer como: falta de desejo do ato sexual (falta de libido), falta de ereção, ejaculação precoce (pode ser considerada também 
um sintoma), ausência de ejaculação ou também falta de sensação de prazer no orgasmo. Algumas inibições, segundo Freud, representam o abandono de uma função, pois realizá-la produziria ansiedade. Na histeria existem mulheres que temem a função sexual. Um sintoma defensivo de repulsa, que seria uma reação frente à experiência de um ato sexual passivo, aparece sempre que a idéia de tal ato é apresentada. Atos obsessivos são uma tentativa de segurança contra experiências sexuais, considerados, portanto, de natureza fóbica.

"A inibição é a expressão de uma restrição de uma função do ego" (Freud, 1926, p. 109). Freud também descobriu que "a função do ego de um órgão fica prejudicada se a sua erotogeneidade - sua significação sexual for aumentada" (p. 110). O ego renuncia a essas funções para não ser necessário ter de usar da repressão como forma de evitar um conflito com o id ou com o superego, porém a idéia persiste de forma inconsciente. Portanto, para Freud (1926), as inibições são "restrições das funções do ego que foram ou impostas como medida de precaução ou acarretadas como resultado de um empobrecimento de energia" (p. 111). Quando a relação sexual é interrompida, ou quando existe abstinência forçada, "o ego fareja certos perigos aos quais reage com ansiedade" (1926, p. 133). Na fobia o ego foge da ansiedade por meio da evitação ou de sintomas inibitórios, sendo a ansiedade apenas um sinal afetivo, uma reação afetiva por parte do ego ao perigo de castração.

Portanto, para a teoria psicanalítica, as dificuldades que surgem na área sexual têm origem na ansiedade de castração para o menino e da perda de amor para a menina.

\section{A PSICOLOGIA DO EGO NAS DISFUNÇÕES SEXUAIS}

Para a psicologia do ego, as dificuldades sexuais, além de se originarem da ansiedade de castração para o menino e da perda de amor para a menina, conforme Freud, procura levar em consideração, também, todas as áreas da vida do ser humano. É necessário ver a pessoa como um todo, onde a aprendizagem influencia o desenvolvimento dela.

Tyson \& Tyson (1993), sugerem que as várias funções do ego estão inter-relacionadas e que, portanto, as funções cognitivas não podem operar isoladamente, não sendo autônomas ou livres de conexões. Para os autores, embora as capacidades cognitivas desenvolvam-se independente do conflito, dependem de uma maternagem adequada, de adequado desenvolvimento dos impulsos, podendo ser perturbadas por conflitos posteriores. Ressaltam que: "o afeto não surge do conflito, mas mais tarde assumem a função de sinalização do perigo em relação ao conflito" (p. 232). O foco sobre os inter-relacionamentos das funções levanta uma questão importante, de 
sobre quais funções surgem do conflito e quais seriam livres de conflito. Porém, o foco é colocado sobre os meios pelos quais os impulsos, funções do ego e fatores ambientais interagem e influenciam uns aos outros durante o desenvolvimento.

A ansiedade e a vergonha surgem entre o $24^{\circ}$ e o $30^{\circ}$ meses e isto indica a internalização do conflito e início da formação do superego. A autoridade é interna e externa e o conflito cada vez mais interno. A ansiedade surge frente a desejos conflituosos, podendo-se observar a vergonha seguindo-se à expressão dos impulsos. "A formação do superego faz exigências posteriores sobre as funções integradoras, organizadoras e reguladoras do ego, de forma que o início da formação do superego implica em avanços no funcionamento do ego" (Tyson \& Tyson, 1993, p. 238).

Ansiedade e vergonha são respostas a uma crítica interna, expressões afetivas que demonstram o nível de organização e integração psíquicas. A respeito da neurose infantil, Tyson \& Tyson (1993), colocam que esta é vista como um novo tipo de organização psíquica integrada. Ela representa uma tentativa de organizar os conflitos, edípicos, pré-edípicos, internos e neuróticos, numa organização única, mais adaptada à realidade e socialmente aceita. Isto representa o nível mais alto de organização psíquica. A neurose infantil pressupõe um funcionamento cada vez mais autônomo do ego, mais independente do apoio externo.

Assim como os neuróticos adultos evitam seus desejos sexuais e agressivos para não entrar em conflito com o superego, para Anna Freud (1946) as crianças tratam seus impulsos instintivos da mesma forma para não transgredirem as proibições de seus pais. "A ansiedade de castração produz nas crianças o mesmo resultado que a ansiedade da consciência nos neuróticos adultos; o ego infantil teme o mundo exterior" (p. 48).

"As situações especificamente evitadas, ou as funções inibidas têm significado instintivo inconsciente (sexual ou agressivo); e é contra este significado instintivo que se dirige, na verdade, a defesa. O que se evita é alusão ou tentação do impulso rejeitado, ou a punição temida; quando não são uma coisa e outra" (Fenichel, 1981, p. 158). As inibições sexuais em geral acontecem em quase todas as neuroses, da timidez ligeira ao ter de abordar o sexo oposto à impotência ou frigidez completas. A inibição pode atuar como aversão às práticas sexuais ou como desinteresse por elas, pode cobrir o campo inteiro da sexualidade ou somente alguns aspectos. Elas podem se manifestar sempre que se apresentem as condições geradoras de temores infantis ou em condições especiais. "Em essência, a impotência e a frigidez não significam que haja material reprimido que volte da repressão, mas são, sim, manifestações clínicas e baluartes da própria defesa" (Fenichel, 1981, p. 159). A impotência é uma defesa desenvolvida pelo ego, impedindo a realização de atividade instintiva considerada perigosa. A parte do ego que impede esta ação é inconsciente, provavelmente oriunda da angústia de castração. O ego renuncia ao prazer 
sexual se este está ligado a perigo intenso (medo de que o pênis possa ser lesado dentro da vagina).

Person (1989, in Fogel, Lane \& Liebert) é da opinião de que além da ansiedade de castração os homens possuem um sentimento de insuficiência e medo em relação à mãe. $\mathrm{O}$ medo da mulher e da incapacidade de satisfazêla (e sua raiva por ela), tem origem em níveis evolutivos diversos, como por exemplo: "medo da mãe pré-edipiana que abandona ou engolfa; da mãe anal que se intromete ou gratifica; da mãe fálica/narcísica que confirma ou deprecia a masculinidade; da mãe edipiana que não pode ser preenchida, que rejeita, que falsamente seduz. A identificação materna, originando-se da inveja, da ansiedade de separação, ou de ambas, desempenha também papel nas preocupações subjacentes à sexualidade masculina" (p. 88).

O núcleo da sexualidade infantil é o complexo de Édipo. Nos casos simples, a impotência baseia-se na persistência de apego sensual inconsciente à mãe. Fenichel (1981) sustenta que superficialmente não existe um apego sexual de todo atraente, pois a parceira nunca é a mãe, ou no caso da menina o pai, mas inconscientemente todo apego sexual tem de ser inibido porque todo o parceiro representa a figura dos pais. $\mathrm{O}$ homem que tem orientação feminina inconsciente pode evitar relações sexuais por causa da angústia; " $i$ sto não significa que a homossexualidade reprima a heterossexualidade, mas, sim, que os mesmos fatores que fizeram o homem homossexual o fazem impotente com as mulheres" (p. 159). Existem graus de impotência, falhas ocasionais, ou até mesmo fraqueza na ereção e análise das ocasiões em que ocorre propicia o entendimento de temores inconscientes. Essas ocasiões mobilizam desejos infantis especiais ou o aumento de certas angústias da infância. Existem casos em que a condição para o bom funcionamento sexual não está ligada ao que se temera na infância, mas " $a$ idéia subjacente é de que a potência só é possível se o homem provar a si mesmo que é capaz, no momento, de enfrentar aquilo que temia no passado (atitude contrafóbica)" (Fenichel, 1981, p. 160).

A ejaculação precoce é considerada uma forma mais grave de impotência e quando crônica é transtorno severo, segundo Fenichel (1981). São característicos de casos de ejaculação precoce crônica sentimentos de culpa em relação a masturbação, que seriam correspondentes de objetivos prégenitais e sádicos da atividade masturbatória. "O paciente procura, no sintoma, inibir a expressão dos objetivos censuráveis, os quais, porém, encontram expressão distorcida" (p. 161).

Nos casos de ejaculação retardada, Fenichel (1981) explica que o sintoma tem um caráter de conversão, que pode exprimir temores inconscientes de castração ou morte ou desejos de caráter sádico ou masoquista, anais (retenção) ou orais (negar-se a dar).

Na mulher, a frigidez exprime inibição de uma experiência sexual completa, cujas raízes estão ligadas a perigo inconsciente análogo à impotência masculina. Atribui-se à educação grande parte na inibição em que é 
feita uma associação entre sexualidade e perigo. Este perigo a evitar representaria o perigo de ferir-se ou de perder o amor da mãe, ou medo da própria excitação, ou da perda de controle (inconscientemente perder o controle dos esfíncteres).

$\mathrm{O}$ vaginismo "liga-se à frigidez tal qual a formação reativa se relaciona com a repressão; não só está inibida a excitação sexual, como algo se faz que garanta a manutenção desta inibição e faça fisicamente impossível o contato" (Fenichel, 1981, p. 163). Algumas vezes o vaginismo não é pura inibição, mas sintoma positivo de conversão, exprimindo com isso não só dificultar a relação sexual como também certo desejo inconsciente distorcido (a inveja do pênis, que leva ao desejo de retê-lo dentro de si).

Kleeman (1982, in Blum), afirma que " $O$ ato de experimentar sensações nos genitais contribui para o primitivo ego corporal, o sentimento do 'self' e a percepção do gênero" (p. 21). Ressalta ainda que a masturbação feminina é intensa e vigorosa durante a segunda metade do segundo ano de vida e que faz parte da natureza feminina, a não ser que a sociedade (pais) transmitam o contrário. $\mathrm{O}$ autor observa, porém, que os meninos no final do segundo ano tem mais conhecimento sobre seu pênis, escroto, testículos e meato urinário do que as meninas sobre seu clitóris, lábios, intróito, ovários, vagina e meato urinário, por serem estes menos visíveis.

Galenson e Roiphe (1982, in Blum), explicam seu tríplice ponto de vista a respeito do desenvolvimento sexual feminino precoce: primeiro, acreditam que a organização do impulso sexual desempenha papel central e modelar para o senso de identidade sexual e que também influencia as relações objetais e o desenvolvimento do ego; segundo, a importância do papel da psicossexualidade pré-edipiana e terceiro que o complexo de castração precoce, com seu componente de inveja do pênis, é fundamental para o desenvolvimento da feminilidade. Principalmente no que diz respeito a substituição erótica da mãe pelo pai como objeto de amor. Com a masturbação, a menina aos dezesseis meses também sofre mudanças comportamentais afetivas, ficando o desenvolvimento do ego sob a influência da catexia genital. "Um caráter definido de organização fálica parece misturar-se $e$, finalmente, predominar sobre a anterior organização anal-urinária" (p. 37). Os autores concordam com Freud quanto à descoberta da menina de que é "castrada" representar um ponto crítico em seu crescimento e desenvolvimento psicossexual, estimulando ou inibindo tendências. Entretanto, acham que esta descoberta ocorre mais cedo, estando intimamente ligadas a temores de perda objetal e anal e modelam um senso de feminilidade já em desenvolvimento, embora vago, originando-se de experiências corporais e afetivas precoces com os pais. As reações de castração variam em intensidade nas crianças, influenciando profundamente o desenvolvimento do ego, intensificando ou inibindo tendências.

Com relação ao sentimento de castração por parte das mulheres, Stoller (1982, in Blum), critica Freud, pois com isto ele ignora todos os aconte- 
cimentos durante o primeiro ano de vida, mais ou menos, que segundo o autor contribuem muito para o desenvolvimento da masculinidade e da feminilidade. Coloca também em questão a inveja do pênis pela menina, indagando como ela pode ter inveja do pênis antes de saber da existência do mesmo.

Stoller (in Blum, 1982) propõe que o desenvolvimento da feminilidade pode ser de dois tipos: neste primeiro, pode ocorrer tanto em mulheres como em homens. A aprendizagem é livre de conflito, ego-sintônica, consistindo em comportamentos com os quais a menina se identifica e/ou é ensinada e encorajada, principalmente pela mãe, que leva ao que ele chama de núcleo da identidade de gênero. Certos comportamentos são aprendidos e mantidos por processos não conflitivos. O desprazer desempenha a função necessária para a criação e manutenção da identidade de gênero. O segundo tipo de feminilidade é o resultado do complexo de Édipo. A mudança da mãe em direção ao pai. Ao preocupar-se em agradar ao pai, através de indícios do meio ambiente e, à medida que compreende e reformula, em sintonia com o desenvolvimento de seu ego, muda sua conduta.

A forma como a menina irá se comportar e sentir durante a puberdade é influenciada pela resposta do ego aos esforços instintuais pré-genitais e fálicos originais e da relação com os objetos primários (pai e mãe). Segundo Ritvo (in Blum, 1982), a forma como a adolescente lida com sua imagem corporal e suas atitudes para com seu corpo serão fundamentais para seu prazer sexual como mulher. Seus sentimentos influenciarão a resposta sexual, intensificando-a ou inibindo-a.

Existem diferenças fundamentais tanto nas estruturas psíquicas, anatômica, na dotação biológica quanto na resposta ambiental entre homens e mulheres. "A consciência e as sensações clitoriais, assim como outras consciências e sensações genitais, contribuem para a experiência corporal feminina e para reações afetivas da menina para seus pais atentos. A imagem corporal feminina é também definida pelo contraste com a masculina e através da identificação e da educação materna" (Bluem, 1982, p. 123).

"A disfunção do orgasmo, ou frigidez como costumava ser chamada, tem sido atribuída, por muitos, a uma defesa contra a ameaça de dissolução do ego" (Moore, in Blum, p. 226). A regressão transitória do ego é necessária para a capacidade orgástica tanto das mulheres como dos homens e o medo inconsciente da regressão do ego impede o orgasmo. Hartmann (1958) acredita que o ego normal deve ser capaz de controlar, mas deve ser capaz de suspender temporariamente suas atividades. Seu exemplo disso é com relação a perda do ego na excitação sexual intensa, onde a ansiedade é da perda do ego no orgasmo.

A seguir, procuro ilustrar o material até aqui apresentado com duas vinhetas, onde elaboro um entendimento dessas disfunções sexuais do ponto de vista freudiano e hartmaniano. 


\section{Vinheta 1}

M., 30 anos, apresenta dificuldade para ter ereção com a namorada. É sua primeira namorada "firme" e estão juntos há dois anos. Com as outras mulheres não tinha dificuldade de ereção, mas trocava com freqüência de parceira. Entende-se seu caso a partir do fato de que tinha uma relação de muita proximidade com a mãe na infância. Filho mais moço de uma prole de três meninos, até os cinco anos dormia no quarto dos pais, depois só quando este não estava, o que era muito repetido, pois o pai trabalhava em dois empregos, dormindo eventualmente em casa. Era tido como uma pessoa rude, que brigava muito com os filhos, provocando muito medo em M. Este sempre foi muito curioso a respeito de sexo e quando entrou na adolescência e iniciou suas relações sexuais estas eram muito freqüentes e com muitas parceiras.

Para Greenson (1998, in Breen), os homens são mais inseguros a respeito de sua masculinidade do que as mulheres sobre sua feminilidade em função da identificação infantil com a mãe. Sob esta perspectiva, onde o paciente tem uma ligação muito forte com a mãe, aliada ao afastamento do pai e sendo este visto como uma figura temida, pensamos não só na ansiedade de castração, conforme Freud, mas também na visão da psicologia do Ego, quanto à insegurança originada pela identificação com a mãe. Suas relações freqüentes e com parceiras diversas tinha o objetivo de aliviá-lo e reassegurá-lo de que não havia sido castrado, de que era homem e possuía um pênis. A partir do momento em que permanece com a mesma parceira, a relação se assemelha com aquela que tinha com a mãe, reativando os temores de castração em função da namorada estar sendo percebida como a figura materna proibida.

As funções do ego estão inter-relacionadas, podendo ser perturbadas por conflitos. Conforme Hartmann (1958), o grau de adaptabilidade é que faz uma pessoa ser bem sucedida ou fracassar numa situação. E essa adaptabilidade vai ser determinada frente às situações ambientais. Segundo o autor, "os organismos vivos 'ajustam-se' notoriamente ao seu meio" (p. 23). Como o homem adquire uma parte importante dos seus processos de adaptação através da aprendizagem e, como Anna Freud (1946) sublinhou, para a criança o mundo externo é um poderoso aliado contra seus impulsos instintivos. Os pais têm, portanto, uma influência muito grande neste processo de adaptação. Refletindo a respeito do caso, o ego do paciente adaptou-se através da disfunção sexual apresentada pelo conflito oriundo de sua relação com os pais. Isso pode ser observado desde o início de suas relações sexuais até o presente, onde então aparece a dificuldade de ter ereção na relação sexual com a namorada. Foi a forma que o ego encontrou de adaptar-se aos conflitos inconscientes. 


\section{Vinheta 2}

S., 32 anos, tem dificuldade de sentir orgasmo com o marido. Foi seu primeiro namorado. Estão casados há 10 anos. Mesmo no namoro S. não conseguia relacionar-se sexualmente com prazer. Achou que com o casamento iria mudar. A mãe nunca conversou sobre sexo com ela, a própria menstruação ela descobriu sozinha. Não tem amigas, nunca foi de ter e é filha única. Sente muita dificuldade de falar sobre sexo. Jamais se masturbou, acha uma coisa feia. O pai era alcoolista e tinha muitas brigas com a paciente e a mãe. O marido também tem problemas com bebida, repetindo com ela o mesmo comportamento que o pai tinha com a mãe.

Para Moore (in Blum, 1982), “... às bases da assim chamada frigidez inerente ao desenvolvimento psicossexual da mulher como individuo, temos de juntar os problemas psicológicos de seu parceiro sexual, sua interação emocional, a adequação da estimulação, a influência hormonal, as circunstâncias sob as quais acontece a relação sexual e várias atitudes sociais e culturais em relação ao sexo" (p. 228). O orgasmo seria, portanto, para a autora, o resultado de um complexo de fisiologia, afeto, fantasia e comportamento que expressaria a organização do ego na experiência pré-genital e genital.

Podemos pensar que são vários os aspectos que dificultam a paciente a ter prazer na relação sexual. O primeiro deles seria a relação com o seu parceiro de aspectos semelhantes ao pai, sua inibição sexual por enxergar o sexo como "sujo", jamais tendo se masturbado ou conversado sobre o assunto com ninguém. Kleeman (1982, in Blum), chama a atenção de que é essencial experimentar as sensações genitais, pois estas contribuem para o primitivo ego corporal, sentimento do "self" e a percepção do gênero. Também os pais podem transmitir que a masturbação é uma coisa errada, que não faz parte da natureza feminina, uma vez que jamais falaram sobre sexo até mesmo na época em que $\mathrm{S}$. menstruou e teve de descobrir tudo por si mesma.

\section{CONCLUSÃO}

Podemos observar que existe uma influência muito grande das idéias de Freud na psicologia do ego. As propostas clássicas da Psicanálise foram respeitadas pelos psicólogos do ego. Isto fica bastante evidente na compreensão dos temores de castração no menino e da perda de amor pela menina. Os sintomas dos pacientes são interpretados basicamente em termos de conflitos entre o ego e o superego, entre as pulsões (do id ou do superego) e o ego, ou entre a realidade e algumas das instâncias psíquicas.

Nos casos dos pacientes, S. e M., aplica-se a situação de que comparações inconscientes do parceiro com o sexo oposto relacionadas com um 
dos pais dificultam o prazer sexual. Podemos pensar que ambos sentem-se diante da representação das figuras materna e paterna respectivamente, e que isso, por sua vez, cause inibição da relação sexual, pois o ego renuncia ao prazer sexual se este está ligado a perigo intenso. Inconscientemente, toda excitação sexual tem de ser inibida. Essas ocasiões mobilizam desejos infantis especiais ou o aumento de certas angústias da infância.

Algumas pessoas permitem relacionar-se sexualmente com outras, mas não podem obter gratificação com o ato, ou seja, obter orgasmo. Outras não permitem sequer ser penetradas ou penetrar. Já outras podem obter orgasmo, mas não com o parceiro com quem estão e tem de fantasiar estarem com outra pessoa, pois esta pode estar representando a figura do pai ou da mãe. Isso vai variar, dependendo do grau de inibição apresentado pelo sujeito. E, conforme a Psicologia do Ego, o desenvolvimento do ego (o órgão específico da adaptação) é determinado por impulsos instintivos e influências do meio, isto é, a aprendizagem dos meios de satisfação e controle dos impulsos instintivos. Conforme Hartmann (1956) "os processos de defesa podem servir, simultaneamente, ao controle do impulso instintivo e à adaptação ao mundo externo" (p. 48). Observa-se a cada passo que o ego efetua, simultaneamente, a adaptação, a inibição e a síntese.

Além da ansiedade de castração provocada por conflitos inconscientes, a importância da relação com os pais e a resolução do conflito edipiano, conforme a teoria freudiana, que aparecem nas duas vinhetas, podemos perceber também, à luz da Psicologia do Ego, outras situações da vida desses dois pacientes que estariam interferindo na vida sexual. Aspectos do desenvolvimento foram influenciados pela aprendizagem na relação com os pais, bem como a questão de que o ego procura adaptar-se, na tentativa de solucionar as demandas pulsionais frente às imposições da realidade, ou seja, frente à relação sexual.

Para o desenvolvimento da feminilidade e da masculinidade a menina e o menino devem se identificar e/ou ser ensinados e encorajados, principalmente pelo pai/mãe que leva à formação do núcleo da identidade de gênero. Kernberg (1995), citando Stoller (1975), ressalta que a identidade de gênero nuclear, o sentimento do indivíduo de ser ou não homem ou mulher, "é determinado pelo gênero atribuído a ele por seus cuidadores durante os primeiros dois a quatro anos de vida, e não por suas características biológicas" (p. 6). Alega ainda que a identidade de gênero, onde a pessoa se identifica com comportamentos típicos em homens ou mulheres de uma determinada sociedade, é fortemente influenciada por fatores psicossociais, assim como a seleção do objeto sexual.

Limitei minha discussão à disfunção sexual feminina e masculina dentro da visão da Psicologia do Ego que, como vimos, apóia-se na teoria freudiana. Percebi que não existem diferenças nas teorias quanto à compreensão das disfunções sexuais, mas sim, que a Psicologia do Ego propõe-se ampliar a compreensão do que se passa, procurando ver o homem 
como um todo. A sexualidade é vista como sendo influenciada, transformada e adaptada, de acordo com as circunstâncias internas e externas do indivíduo, onde o ambiente familiar, atitudes culturais, traumas e processos identificatórios têm um papel fundamental no desenvolvimento psíquico do indivíduo. Mas o realmente sobressai como fator fundamental é o que sempre esteve na teoria freudiana a respeito da ansiedade de castração no menino e do medo da perda do amor por pare da mãe na menina. Através da resolução desses conflitos é que o ego será capaz de lidar com a vida sexual e permitir que tanto homens como mulheres possam usufruir de uma vida sexual satisfatória.

\section{REFERÊNCIAS BIBLIOGRÁFICAS}

BLUM, H. (1977). Psicologia feminina, uma visão psicanalítica contemporânea. Porto Alegre: Artes Médicas, 1982.

BREEN, D. (1993). O enigma dos sexos. Rio de Janeiro: Imago, 1998.

FENICHEL, O. Teoria psicanalítica das neuroses. Rio de Janeiro-São Paulo: Atheneu, 1981.

FOGEL, L. \& L. Psicologia masculina, novas perspectivas psicanalíticas. Porto Alegre: Artes Médicas, 1989.

FREUD, A. (1946). O ego e os mecanismos de defesa. 10. ed. Rio de Janeiro: Civilização Brasileira, 1996.

FREUD, S. (1905). Três ensaios sobre a teoria da sexualidade. E. S. B., v. VII. Rio de Janeiro: Imago, 1976.

. (1923). O ego e o id. E. S. B., v. XIX. Rio de Janeiro: Imago, 1976.

(1924). A dissolução do complexo de Édipo. E. S. B., v. XIX. Rio de Janeiro: Imago, 1976.

- (1925). Algumas conseqüências psíquicas da distinção anatômica entre os sexos. E. S. B., v. XIX. Rio de Janeiro: Imago, 1976.

. (1926). Inibição, sintoma e ansiedade. E. S. B., v. XX. Rio de Janeiro: Imago, 1976.

HARTMANN, H. (1958). A psicologia do ego e o problema de adaptação. Rio de Janeiro: Biblioteca Universal Popular, 1968.

KERNBERG, O. Psicopatologia das relações amorosas. Porto Alegre: Artes Médicas, 1995.

TYSON, P. \& TYSON, R. L. Teorias psicanalíticas do desenvolvimento. Porto Alegre: Artes Médicas, 1993. 